\title{
Boletín Criminológico
}

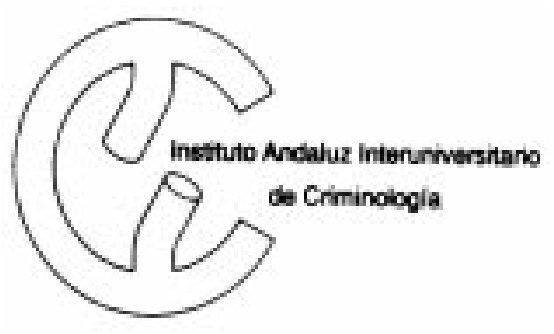

Directora: Per Stangeland.

Coordinadora: Elisa García España

Publicado por la Sección de Málaga del IAIC

Facultad de Derecho, Universidad de Málaga.

Campus de Teatinos, 29071 MALAGA

\section{Boletín Criminológico: Información acrtualizada sobre delincuencia y justicia}

En España existen cuatro Cuerpos de policía: Guardia Civil, Policía Nacional, Policía Autonómica y Policía Local. Cada uno de ellos tiene sus tradiciones, sus razones de ser y su campo de actuación delimitado en leyes y reglamentos. Sin embargo, el público puede quedarse confuso ante tantos uniformes distintos y quizás darse cuenta de que, cuando le hace falta la asistencia policial, no aparecen ninguno de los cuatro. En la guía telefónica existen tres números para llamadas urgentes a la policía: 091 para la Policía Nacional, 092 para la Policía Local y 062 para la Guardia Civil. Es probable que muchos de los ciudadanos que marcan uno de estos números no sepan a quién corresponde ayudarle en su problema y que las actuaciones de los distintos Cuerpos con mucha frecuencia se solapen.

Este trabajo analiza las llamadas realizadas por parte de los ciudadanos de Málaga al teléfono de urgencias de la Policía Local. Este teléfono, el más usado de los tres, recibe cerca de cien mil llamadas al año, de las cuales en este boletín se analizan más detalladamente las llamadas de una semana. En números futuros esperamos poder presentar material sobre la actuación de los demás Cuerpos de policía y así analizar el perfil de trabajo de cada uno.

\section{METODO}

Las llamadas telefónicas al quedan reflejadas en un «MENSATEL» que rellena el operador de la sala del 092 que la recibe, el cual commica el servicio a las unidades de los distintos distritos, reflejando el nomero de llamada, hora de la misma, tipo de requerimiento (particular, organismo oficial...), servicio solicitado, sector de la ciudad, patrulla que atiende la llamada y resultados del servicio. Aleatoriamente se eligió una semana del año cuyo volumen de trabajo no se viera incrementado por circunstancias extraordinarias como la Feria de agosto, Semana Santa, Carnaval, etc.La semana fue la comprendida entre los días 25 de octubre, a las 7.00 horas, y el 1 de noviembre, a la misma hora, de 1993. Se analizó por separado cada uno de los tres turnos en los que se divide cada jornada siendo éstos:

11/4 turno: de 7.00 a $15.00 \mathrm{~h}$.

21/4 turno: de 15.00 a $23.00 \mathrm{~h}$.

$31 / 4$ turno : de 23.00 a 7.00

\section{LLAMADAS DE URGENCIA A LA POLICÍA LOCAL}

\section{INTRODUCCIÓN}

El presente estudio tiene como objetivo primordial plasmar el tipo de servicios que reclama el ciudadano a la policía local a través de las llamadas telefónicas recibidas en la sala del 092.

La investigación realizada se centra sólo y exclusivamente en las llamadas telefónicas que el ciudadano realiza demandando la prestación de un servicio, al cual considera de carácter urgente; por ello, pueden existir variaciones con las estadísticas publicadas en la Memoria de 1993 de la Policía Local. No se incluyen, por tanto, la labor preventiva que efectúan diariamente las unidades policiales, la identificación de personas y vehículos, los servicios programados para el día por los distintos jefes de unidades territoriales, los requerimientos directos del ciudadano en la calle, ni las inter

\section{Boletín Criminológico $N^{o} 7 \quad$ Enero 1995 Página 1}




\section{CLASIFICACIÓN \\ DE LAS LLAMADAS}

Las llamadas se clasificaron en diversos grupos atendiendo a las caracter'sticas del servicio demandado, quedando de la siguiente for ma:

1.- Emergencias criminales: comisión de delitos y faltas.

2.- Emergencias no criminales: accidentes, incendios, inundaciones...

3.- Denuncias-investigación: requerimientos de juzgados, problemática de menores, recuperación de vehículos sustraidos, consumo de drogas en la vía pública, denuncias varias.

4.- Prevención: custodia de viviendas o establecimientos violentados protección de las vías con vallas u otros elementos, apoyo a los distintos servicios municipales como empresa de limpieza, de aguas, de re gulación de sem $\neq$ foros...

5.- Ayuda social: traslados a centros ben •ficos de mendigos y enfermos, asistencia a heridos y otros apoyos sociales.

6.- Peleas y reyertas.

7.- Tráfico: denuncias por infracciones, servicio de grœas, regulaci-n del trłfico rodado...

8.- Ordenanzas municipales: venta ambulante, ruidos en establecimientos nocturnos, inspecciones a los mismos..

9.- Informaciones varias.

venciones surgidas por iniciativa de los propios policías en el desempeño de su labor profesional, como pueden ser denuncias por infracciones de tráfico y de ordenanzas municipales, intervenciones en comisaría por comisión de delitos y faltas, etc.

\section{RESULTADOS}

Los datos obtenidos de las llamadas telefónicas, clasificadas por grupos, arrojaron la siguiente informacion:

\section{TOTAL DE LLAMADAS RECIBIDAS (excepto las que solicitaban información que fueron el $59,6 \%$ del total)}

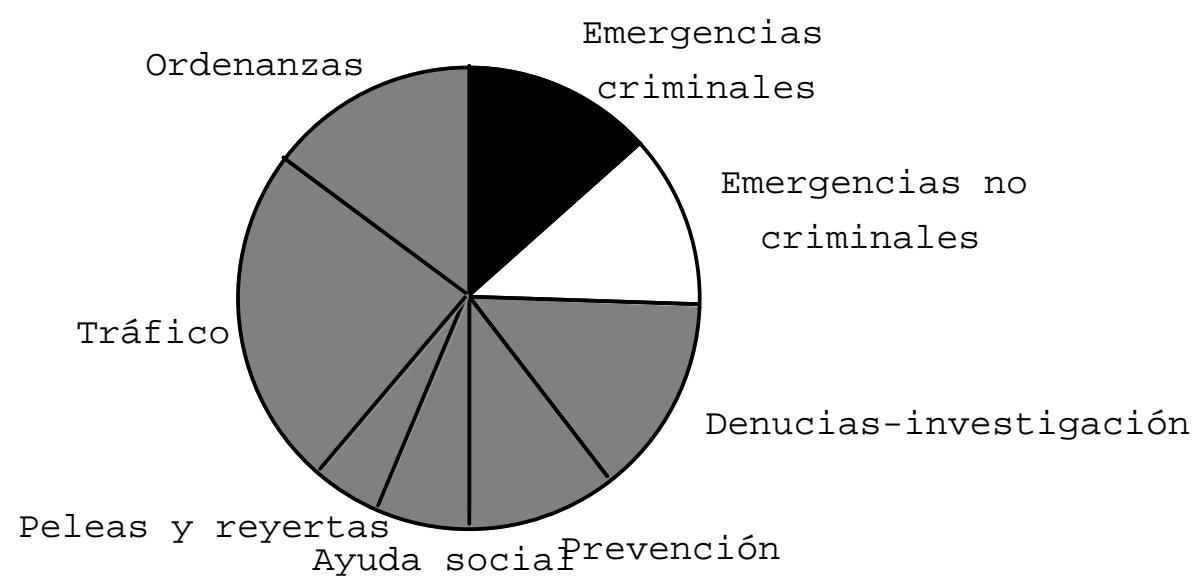

En cuanto a las emergencias criminales, que son las llamadas referentes a la comisión de delitos, por las noches hay más (16,3\%) que en los restantes turnos, debido fundamentalmente a las características propias de la noche (calles poco iluminadas y solitarias, comercios cerrados...) que sirven de amparo al delincuente.

Las llamadas hacen referencia a delitos cometidos mayoritariamente contra la propiedad, principalmente establecimientos comerciales y vehículos estacionados. Le siguen en frecuencia los delitos cometidos contra las personas con intimidación -generalmente con armas blancas- en zonas donde se desarrollan actividades de prostitución.

En el primer y segundo turnos el número de llamadas por delitos es menor y se trata fundamentalmente de robos por el procedimiento del tirón, robos y hurtos en establecimientos comerciales y actuaciones de carteristas en zonas concurridas.

En cuanto a las emergencias no criminales, se observa un mayor equilibrio cuantitativo en los tres turnos ya que el factor horario no influye de forma especial. Destacan los accidentes de tráfico por las noches, sobre todo los fines de semana, con la presencia de grandes aglomeraciones de personas jóvenes y de vehículos, consumo de alcohol y conducción temeraria.

Por lo demás, en el primer y segundo turnos los incidentes tienen

\section{Boletín Criminológico $N^{o} 7 \quad$ Enero 1995 Página 2}




\section{RELACIÓN DE SERVICIOS REALIZADOS \\ A REQUERIMIENTO TELEFÓNICO}

\begin{tabular}{|l|l|l|l|c|}
\hline SERVICIOS & $\mathbf{1}$ TURNO & $\mathbf{2}$ TURNO & $\mathbf{3}$ \% TURNO & TOTAL \\
\hline Emergencia criminal & $\mathbf{1 1 , 3} \%$ & $\mathbf{1 2 , 6} \%$ & $\mathbf{1 6 , 3} \%$ & $13,4 \%$ \\
\hline Emergencia no criminal & $\mathbf{1 1 , 4} \%$ & $\mathbf{1 2 , 7} \%$ & $\mathbf{1 2 , 9} \%$ & $12,3 \%$ \\
\hline Denuncias-investigación & $\mathbf{1 4 , 9} \%$ & $\mathbf{1 8 , 8} \%$ & $\mathbf{7 , 4} \%$ & $13,7 \%$ \\
\hline Prevención & $\mathbf{1 1 , 8} \%$ & $\mathbf{5 , 2} \%$ & $\mathbf{1 2 , 8} \%$ & $9,9 \%$ \\
\hline Ayuda social & $\mathbf{5 , 3} \%$ & $\mathbf{7} \%$ & $\mathbf{8 , 2} \%$ & $6,8 \%$ \\
\hline Peleas y reyertas & $\mathbf{3} \%$ & $\mathbf{4 , 1} \%$ & $\mathbf{6 , 4} \%$ & $4,5 \%$ \\
\hline Tráfico & $\mathbf{3 0} \%$ & $\mathbf{2 9 , 8} \%$ & $\mathbf{1 2} \%$ & $23,9 \%$ \\
\hline Ordenanzas municipales & $\mathbf{1 2 , 1} \%$ & $\mathbf{1 0} \%$ & $\mathbf{2 1 , 4} \%$ & $14,5 \%$ \\
\hline
\end{tabular}

un claro matiz doméstico o fortuito mientras debidos a actos vandálicos y de gamberrismo, como incendios de papeleras, contenedores, vehículos y viviendas.

Existe, con respecto a las llamadas de denuncias-investigación, un incremento en el segundo turno -el de la tarde $(18,8 \%)$ - debido a que la población, una vez terminada su jornada laboral y desocupada, es más receptiva a las irregularidades de su entorno. Asimismo y como consecuencia de la disminución del tráfico rodado, las distintas patrullas disponen de mayor operatividad para proceder a la investigación de denuncias realizadas telefónicamente.

Las llamadas telefónicas calificadas como prevención se incrementan en el tercer turno, es decir, por la noche (12,8\%), atendiendo a alarmas de estableci- mientos comerciales y vehículos, custodia de viviendas, comercios o vehículos robados hasta la localización de los respectivos propietarios, etc. El primer y segundo turnos de prevención están básicamente enfocados a subsanar irregularidades viarias y urbanísticas, apoyo a la circulación y colaboración con distintas áreas del Ayuntamiento y otros organismos.

En el tercer turno hay un incremento de llamadas de ayuda social $(8,2 \%)$ debido a que los distintos indigentes o enfermos mentales son más fácilmente detectables en la vía pública al tener que pernoctar a la intemperie. La ayuda social en estos casos consiste en trasladarlos a un centro de acogida y ponerlos en contacto con los servicios sociales. La ayuda a heridos o enfermos mentales fugados de sus domicilios o de centros especiales se canaliza en coordinación con los servicios de urgencia sanitarios.

Las peleas y reyertas se incrementan por la noche $(6,4 \%)$ debido a la aglomeración de jóvenes, pandillas y tribus urbanas en zonas de ocio los fines de semana. Asimismo, proliferan allí donde se ejerce la prostitución, con enfrentamientos entre prostitutas, clientes y proxenetas. Durante el día suelen ser enfrentamientos vecinales y familiares, y discrepancias derivadas del tráfico.

Con respecto a las llamadas clasificadas de tráfico, éstas se incrementan preferentemente en el primer y segundo turnos (30\% y $29,8 \%$ ) a causa de que el horario laboral intensifica la circulación de vehículos y peatones por las calles. Las llamadas surgen fundamentalmente por estacionamientos en doble fila, en carga y descarga, obstaculización de

\section{Boletín Criminológico $N^{o} 7 \quad$ Enero $1995 \quad$ Página 3}


las vías, apoyos para escolta de transportes especiales,mercancias peligrosas, etc.

Por otro lado nos encontramos con las ordenanzas municipales. Existe una clara diferenciación en los tres turnos ya que en el primer turno las llamadas son fundamentalmente por incidentes en los distintos mercados municipales y mercadillos ambulantes, por infracciones de las ventas ambulantes, ocupación ilegal de la vía y enfrentamientos entre vendedores autorizados e ilegales.

En el segundo turno, al no haber mercados abiertos, las llamadas se focalizan en requerimientos por obras en edificios, ruido de maquinarias, abandono de escombros, etc. En el tercer turno las llamadas son motivadas por la mala insonorización de bares y discotecas, por lo cual la música trasciende al exterior con las consecuentes molestias para los ciudadanos que descansan en sus domicilios.

También se deben las llamadas al incumplimiento de horarios de cierre y a distintas infracciones respecto a la documentación de los establecimientos. Este tipo de llamadas se incrementan considerablemente los fines de semana, llegando a la saturación de las lineas telefónicas de la centralita del 092.

Información representa un 59,6\% del total de las llamadas atendidas durante la semana del estudio, las cuales son directamente resueltas por los operarios de la propia sala del 092. Son llamadas demandando algœn tipo de información, orientación o asesoramiento, que se realizan sobre todo en el primer y segundo turnos. Este tipo de llamadas se han excluido tanto en el gráfico de la página 2 como en el cuadro de la página anterior, por considerarlas menos relevantes.

\section{CONCLUSION}

Se observa como el ciudadano demanda de la Policía Local ser- vicios que abarcan un amplio abanico de situaciones, recogiendo desde infracciones de tráfico y de ordenanzas municipales hastaintervenciones en atracos con utilización de armas. Por ello, se produce con frecuencia duplicidad de servicios con otras Fuerzas de Seguridad, que llevan incluso, en algunas ocasiones, a fricciones y descoordinación entre los distintos Cuerpos policiales, en detrimento del servicio al ciudadano.

Números del Boletín Criminológico publicados hasta la fecha:

1-Víctimas de delincuencia en Málaga (junio 1994) .

2- Discrepancias entre las estadísticas policiales y judiciales (julio y agosto 1994).

3-Ientitud de los procesos penales en Málaga (septiembre 1994).

4- Delinouencia juvenil en Fuengirola (octubre 1994).

5- Ia legalización de la Eutanasia: Seminario intemacional sobre su tratamiento jurídico (novienbre 1994).

6.- Turistas extranjeros víctimas de delitos (dicienbre 1994)

El Boletín Criminológico da un breve resumen de trabajos de investigación llevados a cabo en la Sección de Málaga del I.A.I.C, Facultad de Derecho, Campus de Teatinus, 29071 MALAGA. Se edita un boletín cada mes y la subscripción es gratuita.

Quiero recibir el boletín Criminológico

Nombre

\section{Cargo}

Dirección

\section{Boletín \\ Criminológico \\ $N^{o} 7 \quad$ Enero \\ 1995 \\ Página

